\title{
Biorefinery process for production of bioactive compounds and bio-oil from Camellia oleifera shell
}

\author{
Yunpu Wang ${ }^{1,2,3}$, Linyao $\mathrm{Ke}^{1,2}$, Qi Yang ${ }^{1,2}$, Yujie Peng ${ }^{1,2}$, Yanzhe $\mathrm{Hu}^{1,2}$, Leilei Dai ${ }^{1,2}$, \\ Lin Jiang ${ }^{1,2}$, Qiuhao Wu ${ }^{1,2}$, Yuhuan Liu ${ }^{1,2^{*}}$, Roger Ruan ${ }^{1,2,3}$, Guiming Fu ${ }^{1}$ \\ (1. State Key Laboratory of Food Science and Technology, Nanchang University, Nanchang 330047, China; \\ 2. Engineering Research Center for Biomass Conversion, Ministry of Education, Nanchang University, Nanchang 330047, China; \\ 3. Center for Biorefining and Department of Bioproducts and Biosystems Engineering University of Minnesota, 1390 Eckles Ave.,
} St. Paul, MN 55108, USA)

\begin{abstract}
A biorefinery process was developed in this study to obtain bioactive compounds and bio-oil from Camellia oleifera shells. Four different extraction techniques (water, ethanol, ultrasound-assisted deionized water, and ultrasound-assisted ethanol) were utilized to extract tea saponin and tannin from $C$. oleifera shells. Results showed that ethanol had better extraction capacity than did deionized water, and ultrasound could promote the dissolution of tannin and tea saponin in solution. The thermogravimetric curves of the samples treated under the four conditions moved toward high temperatures. This phenomenon indicated the thermal stability of the residue was significantly improved. The pretreatment showed a slight effect on the chemical compositions of bio-oil. Specifically, the samples treated with ethanol and ultrasound-assisted deionized water contained higher phenol contents $(81.07 \%$ and $81.52 \%$, respectively) than the other samples. The content of organic acid decreased with an increase in the phenol content.
\end{abstract}

Keywords: Camellia oleifera shell, bio-oil, bioactive compounds, biorefinery, ultrasound-assisted extraction, pyrolysis DOI: $10.25165 /$ j.ijabe.20191205.4593

Citation: Wang Y P, Ke L Y, Yang Q, Peng Y J, Hu Y Z, Dai L L, et al. Biorefinery process for production of bioactive compounds and bio-oil from Camellia oleifera shell. Int J Agric \& Biol Eng, 2019; 12(5): 190-194.

\section{Introduction}

Researchers are focusing on sources of clean renewable energy because of the dramatic depletion of nonrenewable energy, such as oil, and the environmental pollution caused by the use of fossil energy. Biomass resources, which are abundant, renewable, and eco-friendly, play an important role in energy supply ${ }^{[1]}$. The conversion of biomass resources to renewable fuels or chemicals by various techniques is thus a hot research topic.

Camellia oleifera shells are regarded as agricultural waste and cannot be treated economically and effectively in most cases. Each ton of $C$. oleifera is processed to produce tea oil along with $0.54 \mathrm{t}$ of $C$. oleifera shells. The main components of $C$. oleifera

Received date: 2018-08-22 Accepted date: 2019-09-19

Biographies: Yunpu Wang, PhD, Associate Professor, research interests: biomass conversion and utilization, Email: wangyunpu@ncu.edu.cn; Linyao Ke, Undergraduate student, research interests: food science and engineering, Email: 2964873235@qq.com; Qi Yang, Undergraduate student, research interests: food science and engineering, Email: 731618236@qq.com; Yujie Peng, Undergraduate student, research interests: food science and engineering, Email: 412558982@qq.com; Yanzhe Hu, Undergraduate student, research interests: food science and engineering, Email: 136164457@qq.com; Leilei Dai, PhD, research interests: food science and engineering, Email: 964255022@qq.com; Lin Jiang, Master, research interests: food science and engineering, Email: 964255022@qq.com; Qiuhao Wu, Master, research interests: food science and engineering, Email: 1142989483@qq.com; Roger Ruan, PhD, Professor, research interests: bioproducts and biosystems engineering, Email: ruanx001@umn.edu; Guiming Fu, PhD, Professor, research interests: research interests: food science and engineering, Email: fuguiming@ncu.edu.cn.

*Corresponding author: Yuhuan Liu, PhD, Professor, research interests: bioproducts and biosystems engineering, Engineering Research Center for Biomass Conversion, Ministry of Education, Nanchang University, Nanchang 330047, China. Tel: +86-791-88333281, Email: liuyuhuan@ncu.edu.cn. shells are cellulose, hemicellulose, lignin, and bioactive substances. According to Luo et al. ${ }^{[2]}$, lignocellulose in C. oleifera shells is a common green carbon-neutral material used for producing new energy sources. Apart from green energy ${ }^{[2]}$, saponins, tannins, xylose, xylitol, furfural, and activated charcoal are produced with use of the lignocellulose in C. oleifera shells ${ }^{[3,4]}$.

Tannins are natural extracts derived from plants and used as processing aids or flavoring substances in the food industry. Chemically, tannins are polyphenolic compounds with molecular weights ranging from $500 \mathrm{Da}$ to $20000 \mathrm{Da}$ and can be classified as condensed and hydrolyzed tannins. Concentrated tannins are mainly obtained from grapes and tea. Meanwhile, the main sources of hydrolyzed tannins are oak and chestnuts ${ }^{[5]}$. C. oleifera is a good source of tea saponin and has not been utilized in the production and processing of tea oil. Tea saponin has good properties, such as powerful foaming, emulsifying, dispersing, and wetting performance ${ }^{[6]}$ and anticancer ${ }^{[7]}$, anti-inflammatory, and antibacterial characteristics. Thus, tea saponin has been widely used in the food, medicine, pesticide, and other fields ${ }^{[82]}$.

In recent years, solvent and supercritical fluids assisted extraction techniques were the most common methods of extracting compounds from plants. Downey et al. ${ }^{[9]}$ investigated the effective range of the extraction of concentrated tannin-containing aqueous ethanol mixtures from Syrah grape skins. They observed the tannin extraction rate of the extracted procyanidins and the solvent type or volume in aqueous solution ${ }^{[9]}$. In the present study, we speculated that the alcohol extraction method may be better than the water extraction. Ultrasound-assisted extraction plays an important role in extracting phenolic compounds from solid materials. Compared with the traditional solvent extraction method, ultrasound-assisted extraction can significantly reduce 
extraction time, energy consumption, and solvent usage. Moreover, the operation is simple and easy ${ }^{[10]}$. The adoption of ultrasound-assisted extraction for extracting pectin from peels and phenolic substances from lees has been investigated ${ }^{[11,12]}$. However, the feasibility of using ultrasound-assisted and solvent extraction to obtain phenolic substances from $C$. oleifera shells has not yet been explored.

C. oleifera shells can be used reasonably and economically. The lignocellulose in the residue is fully utilized and pyrolyzed to produce bio-oil after tannin and tea saponin are extracted. Bio-oil can be used to produce high-value-added chemicals after upgrading ${ }^{[13]}$. Pyrolysis is the main method of converting biomass into energy and chemical products ${ }^{[14]}$. In an oxygen-isolated environment, the biomass organic matrix is broken down at high temperatures and used to produce three substances, namely, solid biochar, bio-oil, and non-condensable gases ${ }^{[15]}$. Fast pyrolysis can increase the yield of bio-oil, whereas slow pyrolysis is used to obtain maximum solid biochar ${ }^{[16]}$. Bio-oil can be used directly as biofuel for power generation, and solid biochar can be further processed to become a soil improver and activated carbon. The adoption of biomass pyrolysis for producing new energy materials has become a frontier research field.

In this study, the effects of different extraction techniques on the extraction yields of tea saponin and tannin were investigated. Thermogravimetric (TG) and pyrolysis gas chromatography/mass spectrometry (Py-GC/MS) analysis techniques were used to analyze the pyrolysis behaviors of residue. This study aims to lay a foundation for the efficient and systematic processing of $C$. oleifera shells.

\section{Material and method}

\subsection{Materials}

C. oleifera shells were purchased from a farm near Nanchang City, Jiangxi Province, China. The samples were sifted using a 60 -mesh sieve and then dried in vacuum at $105^{\circ} \mathrm{C}$ overnight. Proximate and ultimate analyses of the samples are shown in Table 1. An eighty percent ethanol solution was made by mixing anhydrous ethanol with deionized water at a ratio of 4:1. Analytical-grade anhydrous ethanol was obtained from Xilong Scientific Co., Ltd., Shenzhen, China. Deionized water was processed by a laboratory water purification system produced by Hetai Instruments Co., Ltd., Shanghai, China. The ash, fixed carbon, and volatile matter contents of the raw samples were measured according to ASTM e870-82 (2013). The contents of C, $\mathrm{H}, \mathrm{N}$, and $\mathrm{O}$ in the biomass samples were determined using an element analyzer (Vario EL III, Elementar, Hanau, Germany). All experiments were carried out thrice to reduce the experimental error. The high heating value (HHV) was measured by a calorimeter (DYZDHW-6, Hebi Daewoo Instrument Co., Ltd., China).

Table 1 Characteristics of raw sample

\begin{tabular}{|c|c|c|c|c|c|c|c|c|}
\hline \multirow{2}{*}{ Sample } & \multicolumn{3}{|c|}{ Proximate analysis $/ \mathrm{wt} \%^{\mathrm{a}}$} & \multicolumn{4}{|c|}{ Elemental analysis $/ \mathrm{wt} \%{ }^{\mathrm{a}}$} & \multirow{2}{*}{$\begin{array}{c}\mathrm{HHV} \\
/ \mathrm{MJ} \cdot \mathrm{kg}^{-1}\end{array}$} \\
\hline & Ash & Volatile & Fixed carbon & $\mathrm{C}$ & $\mathrm{H}$ & $\mathrm{O}$ & $\mathrm{N}$ & \\
\hline $\mathrm{CS}$ & 1.46 & 75.46 & 23.08 & 46.40 & 6.03 & 45.11 & 0.33 & 18.87 \\
\hline
\end{tabular}

\subsection{Extraction of tannin and tea saponin}

C. oleifera shells were smashed and sifted using an 80-mesh sieve to obtain the $C$. oleifera shell samples. Then, $20 \mathrm{~g} C$. oleifera shell samples were weighted and placed in $500 \mathrm{~mL}$ round-bottom flasks. Deionized water solution and $80 \%$ ethanol solution were added to each flask. The mixture was heated at $70^{\circ} \mathrm{C}$ for $1.5 \mathrm{~h}$ and then filtered to separate the extract and residue under vacuum. Finally, for evaluating the role of ultrasonic assistance, the residue and the extract were collected for all sample groups.

The tea saponin and tannin contents of the extracts of the four groups were measured and recorded. The detailed measurement method has been described in the litereture ${ }^{[17]}$. Meanwhile, residues were dried for subsequent use.

\subsection{TG analysis of $C$. oleifera shell and residue}

TG analysis of $C$. oleifera shell and residue was conducted using a TG analyzer (TGA 4000, PerkinElmer, Waltham, MA, USA) to explore the thermal behavior. Prior to TG analysis, the sample was sifted using a 60 -mesh sieve and then dried to constant weight in vacuum at $105^{\circ} \mathrm{C}$. For a typical experiment, approximately $4 \mathrm{mg}$ of each sample was placed in a ceramic sample pan and high-purity nitrogen was used to provide a pyrolytic experimental inert atmosphere. The nitrogen flow rate was $100 \mathrm{~mL} / \mathrm{min}$. The samples were heated from $30^{\circ} \mathrm{C}$ to $800^{\circ} \mathrm{C}$ at a constant rate of $10^{\circ} \mathrm{C} / \mathrm{min}$.

\subsection{Py-GC/MS analysis of $C$. oleifera shell and residue}

Py-GC/MS analysis was conducted using a double-shot pyrolyzer (PY-2020iD, Binder, Tuttlingen, Germany) coupled with a gas chromatograph/mass spectrometer (GC/MS; Agilent Technologies, Santa Clara, CA, USA) with a chromatographic column (HP-5ms; $30 \mathrm{~m} \times 0.25 \mathrm{~mm} \times 0.25 \mu \mathrm{m}$ ). Approximately $0.5 \mathrm{mg}$ of the sample was introduced into a quartz reactor. High-purity helium was used as the carrier gas to create an inert atmosphere for the Py-GC/MS experiment at a flow rate of $1 \mathrm{~mL} / \mathrm{min}$. The sample was rapidly heated from room temperature to $600^{\circ} \mathrm{C}$ at $20^{\circ} \mathrm{C} / \mathrm{ms}$. The resulting volatiles were analyzed by GC/MS. The helium gas transported the steam generated by the pyrolysis to the injection portion of the GC. The syringe temperature was $250^{\circ} \mathrm{C}$, and a $20: 1$ split ratio was used. The $\mathrm{GC}$ column was heated to $60^{\circ} \mathrm{C}$ for $2 \mathrm{~min}$. Then, the temperature was increased to $280^{\circ} \mathrm{C}$ at $10^{\circ} \mathrm{C} / \mathrm{min}$ for $10 \mathrm{~min}$. MS was operated at an ionization energy of $70 \mathrm{eV}$, and the mass spectrum was obtained at $\mathrm{m} / \mathrm{z} 12$ to 500 . The chemical composition of the pyrolysis vapor was identified by a comparison of its spectrogram with the MS data of the National Institute of Standards and Technology. The relative content of each component of the pyrolysis oil was determined by calculating the peak area percentage.

\section{Results and discussion}

\subsection{Extraction of bioactive substances under different conditions}

Ethanol solutions are commonly used to extract bioactive substances, such as tannin, tea saponin, and active polysaccharides, from biomass. According to the previous study by Tao et al. ${ }^{[12]}$, ultrasound can facilitate the extraction process of bioactive substances.

Figure 1 shows that the $80 \%$ ethanol solution had better extraction capacity than the deionized water for the bioactive substances, regardless of ultrasound-assisted treatment. This finding indicated that the solubility of bioactive substances in organic solvents is higher than that in deionized water. The experimental results also showed that ultrasound-assisted extraction helps extract bioactive substances in two kinds of solutions, and this finding is consistent with those in the previous research ${ }^{[18]}$. In the ultrasound-assisted treatment process, the local pressure in the 
sample suddenly decreased to less than the saturation vapor pressure and formed a cavity. The bubbles burst at high frequencies of vibration, producing shear waves and turbulence of high energy, which caused damage to the cell walls of the samples and facilitated the dissolution of protected bioactive substances ${ }^{[19,20]}$.

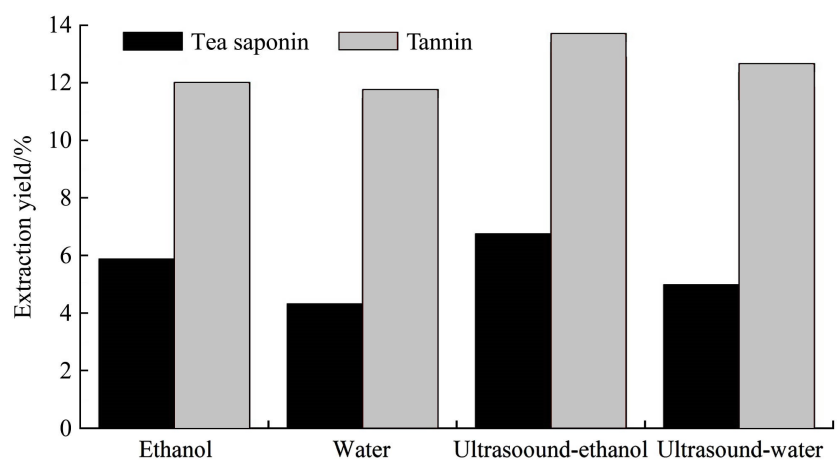

Figure 1 Extraction of bioactive substances under four conditions

\subsection{Pyrolysis of residue}

\subsubsection{TG analysis}

TG and derivative TG (DTG) curves are used to show the relationship between the weight change of a sample and temperature, which allows for an understanding of the behaviors in pyrolysis $^{[21]}$. Figure 2 shows that the pyrolysis behavior could be divided into three stages. In the first stage (from $30^{\circ} \mathrm{C}$ to $\sim 210^{\circ} \mathrm{C}$ ), the sample was decomposed slowly. The volatilization of water and light compounds occurs within this temperature range. In the second stage (from $210^{\circ} \mathrm{C}$ to $\sim 380^{\circ} \mathrm{C}$ ), the remarkable weight loss $(\sim 70 \%)$ was observed due to hemicellulose and cellulose decomposition, which is also the main pyrolysis stage of the samples. Finally, in the third stage (from $400^{\circ} \mathrm{C}$ to $800^{\circ} \mathrm{C}$ ), the residues, such as lignin, were again pyrolyzed slowly ${ }^{[22,23]}$, forming relatively stable char.

In the DTG curve, two characteristic peaks could be observed. The shoulder at $200^{\circ} \mathrm{C}$ to $300^{\circ} \mathrm{C}$ was mainly ascribed to the decomposition of hemicellulose, and the pointed characteristic peak at $300^{\circ} \mathrm{C}$ to $380^{\circ} \mathrm{C}$ was attributed to the decomposition of cellulose. Compared with the pyrolysis of the raw $C$. oleifera shells, the TG and DTG curves of the pretreated samples was removed to the high-temperature zone. This result indicated that the process of extracting tannin and tea saponin from the C. oleifera shells through the four methods contributed to the thermal stability of the cellulose and hemicellulose in the C. oleifera shells. Furthermore, different solvents used in the pretreatment considerably changed the residual weight loss. The samples that was treated with deionized water showed a sharp peak at approximately $350^{\circ} \mathrm{C}$ in the DTG curve. By contrast, the samples that was treated with the ethanol solution exhibited only a gentle shoulder at approximately $350^{\circ} \mathrm{C}$, which indicated that the content of cellulose in the samples treated with deionized water was higher than those from other treatments ${ }^{[24]}$. This phenomenon could be attributed to the difference in extraction content in the samples treated with deionized water, which resulted in prominent peaks ${ }^{[25]}$. Carbon is produced by the dehydration and decomposition of sugar ${ }^{[26]}$. Thus, the char yields $\left(Y_{\text {char }}\right)$ of the samples treated with deionized water were lower than those of the samples treated with the ethanol solution. Differences in the pyrolysis behaviors of the various pretreatment solvents were mainly observed in the range of $330^{\circ} \mathrm{C}$ to $400^{\circ} \mathrm{C}$, indicating that the decomposition temperature of the pretreated samples is nearly in the same range as that of the main components of the sample ${ }^{[27]}$.
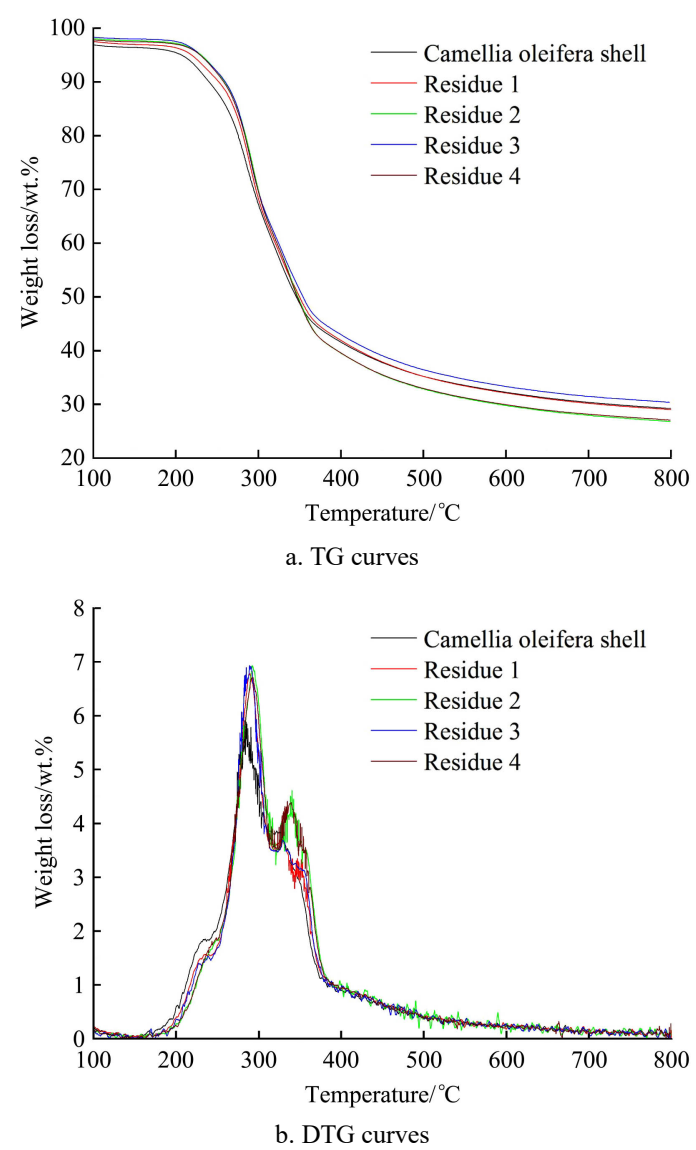

Figure 2 TG and DTG curves of raw sample and residue

The characteristic parameters of the TG and DTG curves are summarized in Table 2 for a further understanding of the pyrolysis behavior of hydrolysate ${ }^{[28]}$. The table also shows that the pretreatment process increased the $T_{i}$ (temperature at which the weight loss was $5 \mathrm{wt} \%$ ) and $T_{m}$ (temperature at which the maximum weight loss rate was obtained) of the samples. This finding also indicated the thermal stability was improved after extraction $^{[29]}$. Compared with the DTG $_{\max }$ (maximum weight loss rate) of the raw samples, that of the samples with pretreatment was substantially better. Thus, the extraction process could promote the pyrolysis of the $C$. oleifera shell samples. A comparison between Samples 1 and 3 or between Samples 2 and 4 showed that ultrasound-assisted extraction could reduce the $T_{i}$ of the samples. The thermal stability of cellulose and hemicellulose was lowered because of the damage caused by ultrasound to the samples.

Table 2 Thermal degradation characteristic of samples ${ }^{\mathrm{a}}$

\begin{tabular}{ccccc}
\hline Samples & $T_{i} /{ }^{\circ} \mathrm{C}$ & $T_{m} /{ }^{\circ} \mathrm{C}$ & $\mathrm{DTG}_{\max } / \% \cdot \mathrm{min}^{-1}$ & $Y_{\text {char }} / \%$ \\
\hline $\mathrm{CS}$ & 206.863 & 283.272 & 5.9045 & 29.23044 \\
1 & 219.255 & 289.222 & 6.7828 & 29.06487 \\
2 & 230.814 & 292.292 & 6.9316 & 26.83285 \\
3 & 229.757 & 288.790 & 6.9319 & 30.41895 \\
4 & 229.536 & 292.765 & 6.7157 & 27.08789 \\
\hline
\end{tabular}

Note: ${ }^{a}$ Run CS represented untreated. $\quad$ Run 1-4 represented ultrasound-ethanol, water, ethanol, ultrasound-water.

\subsubsection{Py-GC/MS analysis}

$\mathrm{Py}-\mathrm{GC} / \mathrm{MS}$ is an efficient tool for analyzing organic matter and an important method of studying the evlution of biomass during pyrolysis $^{[30]}$. On the basis of the different types of chemicals, pyrolysis products are mainly divided into nine categories, including acids, ethers, hydrocarbons, phenols, aldehydes, esters, ketones, amines, and inorganic substances. Information about 
different chemical compositions is summarized in Table 3. Among these compounds, phenols and acids are the two main organic compounds, accounting for approximately $90 \%$ of all. Organic acids contained nearly only acetic acid, which was generated by the removal of acetyl from hemicellulose ${ }^{[28]}$. In the early stages of hemicellulose pyrolysis, with the cracking of the carboxyl group, the formation of acetic acid was caused by the fracture of the 4-O-methyl-D-glucuronic acid base ${ }^{[31]}$. We speculated from the change in the organic acid content produced by five groups of samples in bio-oil that ethanol processing and ultrasound-assisted extraction could reduce the acetyl group in cellulose and hemicellulose, thus reducing the acetic acid in bio-oil. However, in the group of samples treated with ultrasound-assisted ethanol, the content of acetic acid did not reflect this prediction potentially because the methoxy and vinyl groups in the sample were transformed into the precursor organic compounds of acetic acid, such as acetyl, in the ultrasound-assisted ethanol treatment process. This finding could also be confirmed by the reduction in the contents of phenol, 2-methoxy- and phenol, 4,4'-(1-methylethylidene)bis-.

Table 3 Relative contents of main chemical compositions in bio-oil obtained from pyrolysis of each sample ${ }^{\mathrm{a}}$

\begin{tabular}{|c|c|c|c|c|c|c|c|c|c|c|c|}
\hline \multirow{2}{*}{ Compound } & \multicolumn{5}{|c|}{ Relative content $/ \%$} & \multirow{2}{*}{ Compound } & \multicolumn{5}{|c|}{ Relative content $/ \%$} \\
\hline & $\mathrm{CS}$ & 1 & 2 & 3 & 4 & & $\mathrm{CS}$ & 1 & 2 & 3 & 4 \\
\hline Acids & & & & & & Aldehydes & & & & & \\
\hline Acetic acid & 10.19 & 9.58 & 10.41 & 4.91 & 4.14 & Butanal, 3-methyl- & NB & 0.45 & NB & NB & NB \\
\hline Total & 10.19 & 9.58 & 10.41 & 4.91 & 4.14 & Furfural & NB & 1.08 & NB & NB & NB \\
\hline Ethers & & & & & & Total & 0 & 1.53 & 0 & 0 & 0 \\
\hline 1,2,3-Trimethoxybenzene & NB & 0.92 & 1.35 & NB & 0.52 & Esters & & & & & \\
\hline Hydroquinone mono-trimethylsilyl ether & NB & NB & NB & NB & NB & 1,2-Ethanediol, monoacetate & NB & NB & 1.30 & NB & NB \\
\hline Oxirane, (butoxymethyl) & NB & NB & 0.91 & NB & NB & Acetic acid, methyl ester & 0.87 & NB & NB & 1.93 & NB \\
\hline 2,3,5,6-Tetrafluoroanisole & NB & NB & 5.80 & 2.62 & NB & Butyl glyoxylate & NB & NB & NB & NB & 0.72 \\
\hline Glycidol & NB & NB & NB & NB & 0.72 & Total & 0.87 & 0 & 1.30 & 1.93 & 0.72 \\
\hline 1,2-Ethanediol, monoacetate & 0.81 & NB & NB & NB & NB & Ketones & & & & & \\
\hline Total & 0.81 & 0.92 & 8.06 & 2.62 & 1.24 & Acetone & 0.92 & NB & NB & NB & NB \\
\hline Hydrocarbon & & & & & & 2-Cyclopenten-1-one & 0.64 & NB & NB & NB & NB \\
\hline (E)-Stilbene & 3.46 & NB & NB & NB & NB & 2,3-Butanedione & NB & 0.52 & NB & NB & NB \\
\hline Butane & NB & NB & 1.40 & NB & NB & 2-Propanone, 1-(1-methylethoxy)- & NB & 0.87 & NB & NB & NB \\
\hline Pentane & NB & NB & NB & NB & 1.67 & 2-Propanone, 1-hydroxy- & NB & NB & NB & NB & 2.24 \\
\hline 2,2'-Dimethylbiphenyl & NB & NB & NB & NB & 2.18 & $\begin{array}{l}\text { 2,4(1H,3H)-Pyrimidinedione, } \\
\text { 5-(trifluoromethyl)- }\end{array}$ & NB & 4.61 & NB & NB & $\mathrm{NB}$ \\
\hline Total & 3.46 & 0 & 1.40 & 0 & 3.85 & Glycine, N-acetyl- & NB & NB & NB & 1.51 & NB \\
\hline Phenols & & & & & & Total & 1.56 & 6.00 & 0 & 1.51 & 2.24 \\
\hline Phenol, 2-methoxy- & 3.05 & 2.96 & NB & NB & NB & Amine & & & & & \\
\hline Creosol & 0.81 & 1.50 & 2.21 & NB & 0.76 & Methylamine, N,N-dimethyl- & 1.21 & NB & NB & NB & NB \\
\hline Phenol,4-ethyl-2-methoxy- & 1.35 & NB & NB & NB & NB & Tetramethylammonium perchlorate & NB & NB & 1.33 & 1.34 & NB \\
\hline 2-Methoxy-4-vinylphenol & 5.16 & 5.17 & 5.12 & NB & 2.77 & $\begin{array}{l}\text { Ethanamine, 2-hydrazino-N, } \\
\text { N-dimethyl-2-oxo- }\end{array}$ & NB & NB & NB & NB & 1.57 \\
\hline Phenol, 2,6-dimethoxy- & 5.03 & 5.39 & 6.31 & 3.12 & 1.78 & Total & 1.21 & 0 & 1.33 & 1.34 & 1.57 \\
\hline trans-Isoeugenol & 4.94 & 4.67 & NB & 3.30 & 2.59 & Inorganic substance & & & & & \\
\hline Phenol,2,6-dimethoxy-4-(2-propenyl)- & 3.80 & 5.93 & 5.39 & 1.90 & 2.80 & Carbon dioxide & 4.43 & 11.24 & 3.95 & 6.62 & 4.73 \\
\hline Phenol, 4,4'-(1-methylethylidene)bis- & 53.31 & 43.78 & 54.52 & 72.75 & 70.82 & Total & 4.43 & 11.24 & 3.95 & 6.62 & 4.73 \\
\hline Total & 77.45 & 69.13 & 73.55 & 81.07 & 81.52 & & & & & & \\
\hline
\end{tabular}

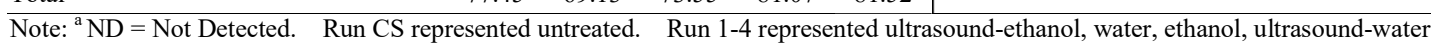

Phenolic compounds in bio-oils are mainly composed of derivatives of phenol, whose content is one of the indices used to evaluate the quality of bio-oil ${ }^{[32]}$. Figure 3 shows that in the two groups of samples treated with different extraction solutions in the pretreatment stage, the effect of ultrasound on the content of phenolic substances in the bio-oils did not show the same rule. The data from the samples after deionized water leaching showed that the samples with ultrasonic assistance during extraction contained a large amount of phenolic compounds. The content of methoxy phenol decreased, and that of alkyl phenol increased significantly. This finding could be attributed to the fact that ultrasound promoted the breaking of methoxy in the sample. For the sample extracted with $80 \%$ ethanol solution, ultrasound-assisted extraction adversely affected the phenol content of the bio-oil produced by the samples possibly because the ultrasound-assisted ethanol extraction reduced the content of hemicellulose and the destruction of alkyl led to a decrease in the content of alkyl phenol. The alkyl phenol content of the bio-oil produced by pyrolysis was higher in the treated samples. Moreover, the content of alkoxyl phenol was low, thereby leading to good bio-oil quality.

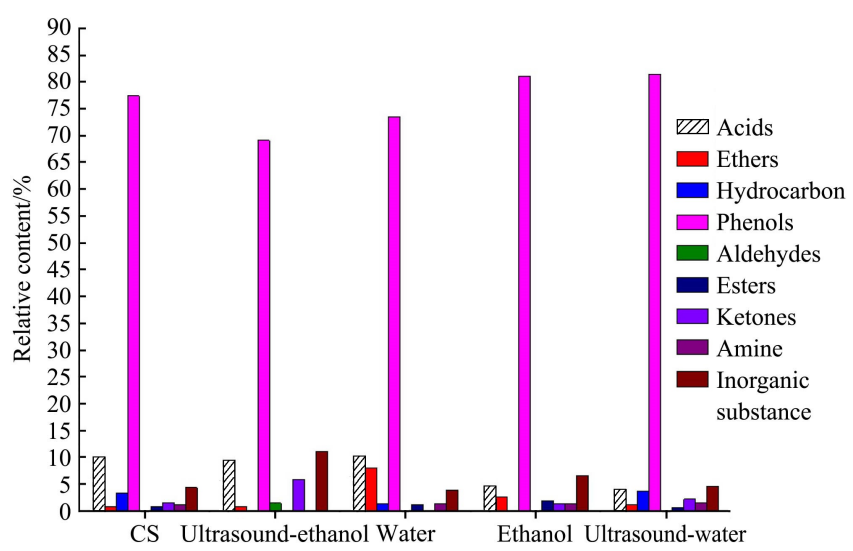

Figure 3 Chemical composition distribution of pyrolysis vapors produced from raw sample and residue

The low content of aldehydes and ketones may be caused by the dissolution of some bioactive substances in the samples by 
pretreatment. Meanwhile, the content of inorganic substances in the bio-oils was also subjected to the same change during filtration as the extraction content of biological active substances. The more the organic matter was dissolved, the higher the content of inorganic matter was. A certain amount of organic acid can reduce the high calorific value of bio-oils ${ }^{[28]}$. According to the above analysis, bio-oil with enhanced quality was obtained from the pyrolysis of samples extracted from ethanol or ultrasonic-assisted deionized water.

\section{Conclusions}

The experimental results showed that the $80 \%$ ethanol solution had better extraction capability for tannins and tea saponin in $C$. oleifera shells than the deionized water. Ultrasound-assisted extraction can facilitate positively the extraction of bioactive substances from the biomass. TG analysis indicated that the process of extracting tannin and tea saponin from the C. oleifera shells through the four methods contributed to the increase of thermal stability of the cellulose and hemicellulose in the $C$. oleifera shells. The content of alkyl phenol produced from pyrolysis increased significantly after treatment with mild ethanol. Ultrasound-assisted deionized water extraction of the $C$. oleifera shells produced the same effect. However, ultrasound-assisted ethanol extraction had no regular effect on the $C$. oleifera shells. Moreover, the content of alkyl phenol decreased, whereas the content of acid increased.

\section{Acknowledgements}

We gratefully acknowledge the financial support from the National Natural Science Foundation of China (No. 21766019), The Key Research and Development Program of Jiangxi Province (20171BBF60023), China Scholarship Council (201806820035), Science and Technology Research Project of Jiangxi Province Education Department (No. GJJ150213), Research Project of State Key of Food Science and Technology (SKLF-ZZB-201722).

\section{[References]}

[1] Doddapaneni T R K C, Konttinen J, Hukka T I, Moilanen A. Influence of torrefaction pretreatment on the pyrolysis of Eucalyptus clone: A study on kinetics, reaction mechanism and heat flow. Industrial Crops and Products, 2016; 92: 244-254.

[2] Lo S-L, Huang Y-F, Chiueh P-T, Kuan W-H. Microwave Pyrolysis of Lignocellulosic Biomass. Energy Procedia, 2017; 105: 41-46.

[3] Zhu J, Zhu Y, Jiang F, Xu Y, Ouyang J, Yu S. An integrated process to produce ethanol, vanillin, and xylooligosaccharides from Camellia oleifera shell. Carbohydrate Research, 2013; 382: 52-57.

[4] Xie Y, Ge S, Jiang S, Liu Z, Chen L, Wang L, et al. Study on biomolecules in extractives of Camellia oleifera fruit shell by GC-MS. Saudi Journal of Biological Sciences, 2018; 25(2): 234-236.

[5] Malacarne M, Nardin T, Bertoldi D, Nicolini G, Larcher R. Verifying the botanical authenticity of commercial tannins through sugars and simple phenols profiles. Food Chemistry, 2016; 206: 274-283.

[6] Feng J, Chen Y, Liu X, Liu S. Efficient improvement of surface activity of tea saponin through Gemini-like modification by straightforward esterification. Food Chemistry, 2015; 171: 272-279.

[7] Zong J, Wang R, Bao G, Ling T, Zhang L, Zhang X, et al. Novel triterpenoid saponins from residual seed cake of Camellia oleifera Abel. show anti-proliferative activity against tumor cells. Fitoterapia, 2015; 104: 7-13.

[8] Wu H, Li C, Li Z, Liu R, Zhang A, Xiao Z, et al. Simultaneous extraction of oil and tea saponin from Camellia oleifera Abel. seeds under subcritical water conditions. Fuel Processing Technology, 2018; 174: 88-94.

[9] Downey M O, Hanlin R L. Comparison of ethanol and acetone mixtures for extraction of condensed tannin from grape skin. South African Journal of Enology and Viticulture, 2010; 31(2): 154.
[10] Tao Y, Sun D-W. Enhancement of food processes by ultrasound: A review. Critical Reviews in Food Science and Nutrition, 2015; 55(4): 570-594.

[11] Yang Y, Wang Z, Hu D, Xiao K, Wu J-Y. Efficient extraction of pectin from sisal waste by combined enzymatic and ultrasonic process. Food Hydrocolloids, 2018; 79: 189-196.

[12] Tao Y, Wu D, Zhang Q A, Sun D W. Ultrasound-assisted extraction of phenolics from wine lees: modeling, optimization and stability of extracts during storage. Ultrasonics Sonochemistry, 2014; 21(2): 706-715.

[13] Isahak W N R W, Hisham M W M, Yarmo M A, Yun Hin T-Y. A review on bio-oil production from biomass by using pyrolysis method. Renewable and Sustainable Energy Reviews, 2012; 16(8): 5910-5923.

[14] Dai L, Wang Y, Liu Y, Ruan R, He C, Yu Z, et al. Integrated process of lignocellulosic biomass torrefaction and pyrolysis for upgrading bio-oil production: A state-of-the-art review. Renewable and Sustainable Energy Reviews, 2019; 107: 20-36.

[15] Kan T, Strezov V, Evans T J. Lignocellulosic biomass pyrolysis: A review of product properties and effects of pyrolysis parameters. Renewable and Sustainable Energy Reviews, 2016; 57: 1126-1140.

[16] Nachenius R W, Ronsse F, Venderbosch R H, Prins W. Chapter Two Biomass Pyrolysis. In: Murzin D Y, editor. Advances in Chemical Engineering. Academic Press, 2013; pp.75-139.

[17] Sun F F, Tang S, Liu R, Tang Y, Wang R, Zhang Z, et al. Biorefining fractionation of the Camellia oleifera Abel. hull into diverse bioproducts with a two-stage organosolv extraction. Industrial Crops and Products, 2016; 94: 790-799.

[18] Patist A, Bates D. Ultrasonic innovations in the food industry: From the laboratory to commercial production. Innovative Food Science \& Emerging Technologies, 2008; 9(2): 147-154.

[19] Laborde J L, Bouyer C, Caltagirone J P, Gérard A. Acoustic bubble cavitation at low frequencies. Ultrasonics, 1998; 36(1): 589-594.

[20] Moholkar V S, Rekveld S, Warmoeskerken M M C G. Modeling of the acoustic pressure fields and the distribution of the cavitation phenomena in a dual frequency sonic processor. Ultrasonics, 2000; 38(1): 666-670.

[21] Zheng Y, Tao L, Yang X, Huang Y, Liu C, Zheng Z. Study of the thermal behavior, kinetics, and product characterization of biomass and low-density polyethylene co-pyrolysis by thermogravimetric analysis and pyrolysis-GC/MS. Journal of Analytical and Applied Pyrolysis, 2018; 133: 185-197.

[22] Striūgas N, Skvorčinskienė R, Paulauskas R, Zakarauskas K, Vorotinskienė L. Evaluation of straw with absorbed glycerol thermal degradation during pyrolysis and combustion by TG-FTIR and TG-GC/MS. Fuel, 2017; 204: 227-235.

[23] Zhang S, Dong Q, Zhang L, Xiong Y. Effects of water washing and torrefaction on the pyrolysis behavior and kinetics of rice husk through TGA and Py-GC/MS. Bioresource Technology, 2016; 199: 352-361.

[24] Chen D, Zhou J, Zhang Q. Effects of Torrefaction on the Pyrolysis Behavior and Bio-Oil Properties of Rice Husk by Using TG-FTIR and Py-GC/MS. Energy \& Fuels, 2014; 28(9): 5857-5863.

[25] Wang Z, He Z, Zhao Z, Yi S, Mu J. Influence of ultrasound-assisted extraction on the pyrolysis characteristics and kinetic parameters of eucalyptus. Ultrasonics sonochemistry, 2017; 37: 47-55.

[26] Dhyani V, Bhaskar T. A comprehensive review on the pyrolysis of lignocellulosic biomass. Renewable Energy, 2017; 129: 695-716.

[27] Mészáros E, Jakab E, Várhegyi G. TG/MS, Py-GC/MS and THM-GC/MS study of the composition and thermal behavior of extractive components of Robinia pseudoacacia. Journal of Analytical and Applied Pyrolysis, 2007; 79(1-2): 61-70.

[28] Dai L, He C, Wang Y, Liu Y, Ruan R, Yu Z, et al. Hydrothermal pretreatment of bamboo sawdust using microwave irradiation. Bioresource Technology, 2018; 247: 234-241.

[29] Dai L, He C, Wang Y, Liu Y, Yu Z, Zhou Y, et al. Comparative study on microwave and conventional hydrothermal pretreatment of bamboo sawdust: Hydrochar properties and its pyrolysis behaviors. Energy Conversion and Management, 2017; 146: 1-7.

[30] Gao N, Li A, Quan C, Du L, Duan Y. TG-FTIR and Py-GC/MS analysis on pyrolysis and combustion of pine sawdust. Journal of Analytical and Applied Pyrolysis, 2013; 100: 26-32.

[31] Richards G N. Glycolaldehyde from pyrolysis of cellulose. Journal of Analytical and Applied Pyrolysis, 1987; 10(3): 251-255.

[32] Cheng F, Brewer C E. Producing jet fuel from biomass lignin: Potential pathways to alkyl-benzenes and cycloalkanes. Renewable and Sustainable Energy Reviews, 2017; 72: 673-722. 